\title{
Growth Hormone Inhibiting Hormone Measurement
}

National Cancer Institute

\section{Source}

National Cancer Institute. Growth Hormone Inhibiting Hormone Measurement. NCI Thesaurus. Code C74861.

The determination of the amount of growth hormone inhibiting hormone present in a sample. 